\title{
Reaction time as a function of age, anxiety, and typicality
}

\author{
JOHN H. MUELLER, DONALD H. KAUSLER, ANGELA FAHERTY, \\ and MICHAEL OLIVERI \\ University of Missouri, Columbia, Missouri 65211
}

\begin{abstract}
Elderly adults were compared with high and low test-anxious young adults on a task that required deciding whether a word could be considered an instance of the category name shown with it. The words were either typical or atypical members of the category. The elderly adults showed the slowest reaction times for all decisions, and the age difference was proportionally the same for atypical and typical instances. Elderly subjects were more like highanxiety young adults than like low-anxiety young adults for atypical instances, but elderly subjects were significantly worse than anxious young adults for typical instances and unrelated words. These results offer some support for the role of anxiety in producing the aging performance deficit, but this factor seems insufficient to explain all age-related performance differences.
\end{abstract}

Numerous studies have been concerned with age differences in reaction time (e.g., Cerella, Poon, \& Williams, 1980). In one recent experiment, Mueller, Kausler, and Faherty (1980) examined speed of access for various types of information. Young and elderly subjects were required to decide whether two words were spelled the same, were pronounced alike, or belonged to the same category. Elderly subjects took longer than young adults to make all three types of decisions, but overall there was little age difference between spelling and category matches in terms of proportional deficit. That is, while the age difference was greater for semantic than for nonsemantic decisions, the elderly were about $41 \%$ slower for both types of matches because semantic decisions took more time in general. The only evidence of a disproportional age difference was for category decisions that led to a "no" response. Elderly subjects took more time to decide that two words did not belong to the same category, as if their criterion for including items within a category was not as well defined as was that of young adults. This outcome seems consistent with previous findings by Eysenck (1975), in that a decision process is implicated in the aging deficit, although a decision different from that implied by Eysenck (1975).

If category "boundaries" are less well-defined for the elderly, then differences between young and elderly subjects should be minimized for "good" examples of the category and maximized for "poor" examples. When the decision involves a typical instance, no subject should require very long, regardless of age. However,

Requests for reprints should be sent to John Mueller, Psychology Department, 210 McAlester Hall, University of Missouri, Columbia, Missouri 65211. This research was supported in part by NIA-USPHS Grant 1R01AG01485-02 to D. H. Kausler. when the matching decision involves an atypical example, the elderly may require more time than young adults if the category boundary is poorly defined for older subjects. The main purpose of the present study was to examine age differences in category boundaries. The procedure was similar to that used by Eysenck (1975) and Freedman and Loftus (1971). Subjects were presented a category name plus a word and had to decide whether the word was a member of the category. The preceding analysis implies that the age difference should be greater for atypical instances than for typical instances.

The second factor of interest here was the relationship between age and anxiety-arousal level. One explanation for the memory deficit observed in elderly subjects is a higher arousal level, either of a chronic nature or specifically in response to the threat of evaluation (e.g., Eisdorfer \& Wilkie, 1977; Eysenck, 1977). This is a reasonable hypothesis, but the data are somewhat mixed: Some studies have found elderly subjects to be more anxious than young adults in terms of selfreport questionnaires (e.g., Whitbourne, 1976), others have not (e.g., Mueller et al., 1980; Mueller, Rankin, $\&$ Carlomusto, 1979). In fact, Hutto and Smith (Note 1) found a decline in state anxiety between the ages of 25 and 69 years.

Interestingly, Mueller et al. (1980) did obtain a reaction time pattern consistent with the aging-arousal hypothesis. That is, Schwartz (1979) found that arousal had a greater slowing effect on category-matching speed than on nonsemantic matches. If the aged are more aroused, then such a pattern is essentially in accord with the results of Mueller et al. (1980), although their self-report anxiety data did not corroborate the ageanxiety interpretation. This outcome becomes more pertinent in view of the results of the experiment reported here. 
The present study tested the aging-anxiety hypothesis by using two groups of young adults, half high in test anxiety and half low. Comparable patterns for decision times between young high-anxiety and elderly subjects would be consistent with the anxiety hypothesis. However, if the elderly are slower than the young highanxiety subjects, then one possible interpretation is that more than differential anxiety is involved in the aging deficit. In addition to preselecting young adults on the basis of extreme anxiety scores, we administered postexperimental anxiety questionnaires to all subjects as a check on situational anxiety.

\section{METHOD}

\section{Subjects}

The young adults were 26 undergraduates recruited from introductory psychology courses. Their average age was 18.6 years, with 13.2 years of formal education. The young adults were selected as high or low in test anxiety, using scores on Spielberger's (1980) Test Anxiety Inventory. This questionnaire has 20 items, each scored on a 1-4 scale. The young highanxiety subjects had scores above 50 (mean $=57.7$ ), and the young low-anxiety subjects had scores below 31 (mean $=27.8$ ). The 13 elderly adults were recruited from the Columbia community and paid $\$ 4$ for travel expenses. Their average age was 70.5 years, with 17.2 years of formal education. The elderly subjects showed significantly higher verbal ability (WAIS, Items 21-40) than the young adults (means $=29.4$ and 18.2) $[F(2,34)=13.14]$. There were seven men and six women in each of the three groups.

\section{Materials}

Fifteen category names were selected. (McCloskey \& Glucksberg, 1978), and each was paired twice with a typical instance (e.g., ANIMAL-DOG), twice with an atypical exemplar (e.g., ANIMAL-TADPOLE), and four times with a typical instance of some other category. The latter "unrelated" pairings involved new instances altogether, not instances that were correctly paired elsewhere in the set. Thus there were 60 pairs yielding a "yes" response and 60 yielding a "no" response. For the correct pairings, a "typical" exemplar was defined as an instance with a value above 9.1 in the norms (maximum of 10), and "atypical" instances had values below 7.3. The 120 pairs were presented twice, in different orders, with a 30 -sec rest period between the two blocks.

\section{Procedure}

The pairs were presented one at a time on a CRT controlled by a PDP-11/34 computer. The category name appeared on the left in parentheses, with the test instance on the right. Subjects indicated their decision by pressing one of two keys at the typewriter console for "yes" or "no." They were instructed to respond quickly but accurately. Following the second presentation of the 120 pairs, the subjects completed the 20-item State-Trait Anxiety Inventory (Spielberger, Gorsuch, \& Lushene, 1970) and Whitbourne's (1976) Anxiety Achievement Test. Both were administered on the CRT and were self-paced.

The final stage of the experiment was a cued recall test, as a measure of incidental learning. Subjects were given recall sheets with the 15 category names followed by eight blank lines after each name, and they were allowed up to $8 \mathrm{~min}$ to fill in as many of the instances from each category as they could remember. Perfect recall would be two typical instances that had been paired with the name, two atypical instances that had been paired with the name, and four typical instances that had been paired with some other name.

\section{RESULTS}

\section{Matching Task}

The decision times were analyzed in a 3 (group: young high-anxiety, young low-anxiety, elderly) by 3 (instance type: typical, atypical, unrelated) by 2 (block) mixed factorial, with repeated measures on the last two factors. Effects described as significant involved $\mathrm{p}<.05$. Table 1 summarizes the reaction time data for each condition; only correct responses were considered.

The groups main effect was significant $[\mathrm{F}(2,36)=$ $10.64, \mathrm{MSe}=452,921.4]$. Individual comparisons showed the young high-anxiety subjects (mean $=1,580.7 \mathrm{msec}$ ) to be significantly faster than the elderly (mean $=1,812.8$ ) but significantly slower than the young low-anxiety subjects (mean $=1,316.1)$.

The instance-type main effect was significant $[\mathrm{F}(2,72)=68.40, \mathrm{MSe}=46,142.1]$. Individual comparisons showed the unrelated instances (mean = $1,545.9 \mathrm{msec})$ to be significantly slower than typical instances (mean $=1,381.7)$ and significantly faster than atypical instances $($ mean $=1,781.9)$.

The blocks main effect showed merely faster times on the second block $[F(1,36)=99.03, \mathrm{MSe}=66,219.3]$. Although the Groups by Block interaction was not significant $(F<1)$, the Instance by Block interaction was significant $[F(2,72)=26.12, \quad M S e=18,400.9]$. Typical instances and unrelated instances were only $150-200 \mathrm{msec}$ faster on the second test than on the first, but atypical instances were about $500 \mathrm{msec}$ faster; on Block 2, typical instances were faster (mean = $1,259 \mathrm{msec})$ than unrelated $(1,424 \mathrm{msec})$ and atypical $(1,523 \mathrm{msec})$ instances, and the last two did not differ.

The only interaction involving the group factor was a marginally significant Groups by Instance interaction $[\mathrm{F}(4,72)=2.48, \mathrm{MSe}=46,142.1, \mathrm{p}<.06]$. As can be seen in Table 1 , the two young groups were comparable but faster than the elderly group for typical and unrelated instances, whereas the elderly and the young highanxiety groups were comparable for atypical instances. In other words, for typical and unrelated instances, the grouping by similar performance is in terms of age, but for atypical instances, the comparability is as would be expected if elderly subjects were high in anxiety.

The analysis of errors revealed that elderly subjects made significantly fewer misclassifications than did the

Table 1

Mean Reaction Time (RT) in Milliseconds and Errors (E) by Instance Type and Age

\begin{tabular}{|c|c|c|c|c|c|c|}
\hline \multirow[b]{2}{*}{ Instance } & \multicolumn{2}{|c|}{ Elderly } & \multicolumn{2}{|c|}{$\begin{array}{l}\text { High-Anxiety } \\
\text { Young }\end{array}$} & \multicolumn{2}{|c|}{$\begin{array}{c}\text { Low-Anxiety } \\
\text { Young }\end{array}$} \\
\hline & RT & $\mathrm{E}$ & RT & $\mathrm{E}$ & RT & $\mathrm{E}$ \\
\hline Typical & 1615.1 & .5 & 1369.6 & 1.1 & 1160.6 & .7 \\
\hline Atypical & 2001.8 & 3.5 & 1874.7 & 6.5 & 1469.3 & 5.7 \\
\hline Unrelated & 1821.5 & 1.7 & 1497.8 & 2.9 & 1318.5 & 3.0 \\
\hline
\end{tabular}


young adult groups (means $=1.94,3.47,3.13)[\mathrm{F}(2,36)$ $=13.30, \mathrm{MSe}=3.82]$. Not surprisingly, there were more errors on the atypical instances than on the unrelated or typical instances (means $=5.23,2.53, .78$ ) $[F(2,72)=56.65, \mathrm{MSe}=6.92]$. An Instance by Block interaction revealed that errors for typical and unrelated instances remained stable over blocks, whereas errors declined for atypical instances, but atypical instances were still misclassified more often than were the other types $[\mathrm{F}(2,72)=9.78, \mathrm{MSe}=1.82]$. The correlation between decision latency and errors was not significant for any of the three types of instances (rs <.17).

\section{Recall}

The cued recall results are shown in Table 2. Recall was scored for three types of items: those that had been paired with the category name for a decision during the matching task, either typical or atypical, and items that had not been paired with the appropriate category name ("unrelated," or "cross-paired").

There was no group effect for the recall of typical instances $[\mathrm{F}(2,36)=1.19]$ or unrelated instances $[F(2,36)=1.42]$. However, the young low-anxiety subjects recalled significantly more atypical instances than did the elderly or young high-anxiety subjects $($ means $=17.4,14.7,13.1)[\mathrm{F}(2,36)=4.81, \mathrm{MSe}=12.80]$. That fewer cross-paired typical instances were recalled than paired typical instances seems consistent with the encoding-specificity principle (Tulving \& Thomson, 1973), and there was no obvious age difference. That is, relative to paired typical recall, the elderly recalled $31 \%$ as many cross-paired typical items, compared with about $36 \%$ for the young adults.

It was also possible to analyze intrusions in recall, specifically members of the category that had not been used in the experiment. Elderly subjects made more "good guesses" of this type than did either young highanxiety or young low-anxiety subjects (mean $=4.6$, $2.9,2.0)$, but the difference was not significant $[\mathrm{F}(2,36)$ $=1.21]$.

\section{Self-Report Anxiety}

The state anxiety scores showed comparable values for the elderly, young high-anxiety, and young lowanxiety groups (means $=52.0,53.6,54.8)[\mathrm{F}(2,36)=$ $1.36]$. However, the groups main effect was significant for both the "debilitating" and the "facilitating" subscales of the Anxiety Achievement Test $[\mathrm{Fs}(2,36)=$

Table 2

Mean Correct Recall by Age Group and Item Type

\begin{tabular}{lccc}
\hline & Elderly & $\begin{array}{c}\text { High- } \\
\text { Anxiety } \\
\text { Young }\end{array}$ & $\begin{array}{c}\text { Low- } \\
\text { Anxiety } \\
\text { Young }\end{array}$ \\
\hline Paired Typical & 17.7 & 19.8 & 20.3 \\
Paired Atypical & 14.7 & 13.1 & 17.4 \\
Unpaired Typical & 5.5 & 7.1 & 7.5 \\
Total & 37.9 & 39.9 & 45.2 \\
\hline
\end{tabular}

21.66 and 9.62, MSes $=2.84$ and 1.89]. In terms of the debilitating subscale, young high-anxiety subjects reported more anxiety than either the elderly or young low-anxiety subjects (means $=5.9,3.2,1.6$ ). For the facilitating subscale, high test-anxious young adults scored higher than elderly or young low-anxiety subjects (means $=5.2,3.0,3.2$ ), the latter two not differing. Thus, even though on some measures elderly subjects were similar to young high-anxiety subjects, this was not true for self-report anxiety.

There was a nonsignificant tendency for the elderly subjects to rate the matching task as requiring more effort than the young adults reported $[F(2,36)=2.94$, $\mathrm{p}<.06]$. There was no difference between the groups for rated difficulty or distraction $\left(F_{s}<1\right)$.

\section{DISCUSSION}

Considering the question of category boundaries first, the present data seem inconsistent with the hypothesis that elderly adults have less sharply defined criteria for including or excluding items as instances of some superordinate label. Atypical instances required more time for a category membership decision than typical instances, but this was true for each age group. For example, comparing the reaction times of the elderly subjects (Table 1) with the average of the two young adult conditions, the elderly showed a deficit of about $28 \%$ for typical instances, $20 \%$ for atypical instances, and $29 \%$ for unrelated instances. The somewhat smaller age deficit for atypical items may be due to greater verbal fluency in the elderly group; however, the correlations between verbal scores and latency did not reach significance for any instance type (rs $<.21)$. Viewed somewhat differently, the elderly were $24 \%$ slower for atypical instances than for typical instances, whereas the young high- and low-anxiety groups were $37 \%$ and $27 \%$ slower.

Thus, within the constraints of the present procedures, it appears that the elderly do not differ from young adults in terms of deciding about marginal category members, at least no more so than is also true for "good" exemplars. This was apparent in the recall data as well, in which, if anything, the elderly did not show as much of a decline in recall for atypical instances relative to typical instances as was the case for the young adults. Thus both the reaction time and recall data seem consistent with studies that have shown taxonomic category data to be essentially the same for young and elderly adults (Howard, 1980). It could be that slower speeds should result for atypical examples regardless of age, with only actual decision outcomes differing. However, detailed examination of classification decisions for typical and atypical instances by age was not feasible here, as there were very few cases in which the young and elderly consistently disagreed on an atypical instance, as validated by the low "error" rates here (Table 1).

The preceding conclusions are somewhat qualified by the second factor in the study. In some respects, elderly subjects performed very much like the anxious young adults, particularly for atypical instances. This may indicate that typicality does have some age-related effect after all, but, more important, this outcome is consistent with the hypothesis that overarousal may underlie the age difference in performance. Admittedly, the deficit could occur for the elderly and anxious young adults for different reasons, but the finding of similar performances by these two groups is in accord with the age-anxiety hypothesis. However, for typical instances, the deficit seems to be more one of age, as the high-anxiety young adults were more like their low-anxiety age mates than were the elderly adults. Within the two young adult groups, anxiety seemed to have a greater slowing effect for atypical instances, as expected (cf. Eysenck, 1977). 
The main problem with the age-anxiety hypothesis here is that the postexperimental anxiety measures did not corroborate the grouping by performance. That is, while the young highanxiety subjects were more anxious than their age mates, the elderly were no more anxious than the young low-anxiety subjects. This failure to find elderly subjects more anxious on postexperimental self-report questionnaires is consistent with previous studies (e.g., Mueller et al., 1979; Mueller et al., 1980). This may indicate problems with the self-report measures in general or, specifically, their use with elderly subjects. It may be that the elderly were more concerned with appearing socially acceptable, thus underplaying their anxiety, or perhaps the elderly do not experience evaluative anxiety in these settings. For example, perhaps the young experimenter is not enough of an authority figure, or possibly the task is perceived as intrinsically interesting. It is also possible that self-report anxiety measures are not wholly congruent with variations in physiological arousal. Whatever the ultimate explanation may be, it seems best for now not to rule out arousal differences as one factor in the performance deficit associated with aging. Even at that, though, it should be noted that the elderly were still somewhat slower than the anxious young adults, indicating that more than higher arousal is involved in the performance deficit.

\section{REFERENCE NOTE}

1. Hutto, G. L., \& Smith, R. C. The self-report of anxiety in adults: The effects of age and other variables on STAI scores. Paper presented at the meetings of the Southwestern Psychological Association, Oklahoma City, 1980.

\section{REFERENCES}

Cerella, J., Poon, L. W., \& Williams, D. M. A quantitative theory of mental processing time and age. In L. W. Poon (Ed.), Aging in the 1980s: Selected contemporary issues in the psychology of aging. Washington, D.C: American Psychological Association, 1980.
Eisdorfer, C., \& Wilkie, F. Stress, disease, aging and behavior. In J. E. Birren \& K. W. Schaie (Eds.), Handbook of the psychology of aging. New York: Van Nostrand Reinhold, 1977.

Eysenck, M. W. Retrieval from semantic memory as a function of age. Journal of Gerontology, 1975, 30, 174-180.

EySENCK, M. W. Human memory: Theory, research and individual differences. Oxford: Pergamon Press, 1977.

Freedman, J. L., \& Loftus, E. F. The retrieval of words from long-term memory. Journal of Verbal Learning and Verbal Behavior, 1971, 10, 107-115.

How ARD, D. V. A comparison of the Battig and Montague (1969) norms with the responses of adults between the ages of 20 and 80 . Journal of Gerontology, 1980, 35, 225-231.

McCloskey, M. E., \& Glucksberg, S. Natural categories: Well defined or fuzzy sets? Memory \& Cognition, 1978, 6, 462-472.

Mueller, J. H., Kausler, D. H., \& Faherty, A. Age and access time for different memory codes. Experimental Aging Research, 1980, 6, in press.

Mueller, J. H., Rankin, J. L., \& Carlomusto, M. Adult age differences in free recall as a function of basis of organization and method of presentation. Journal of Gerontology, 1979, 34, 375-380.

Schwartz, S. Differential effects of personality on access to various long-term memory codes. Journal of Research in Personality, 1979, 13, 396-403.

Spielberger, C. D., Gorsuch, R. L., \& Lushene, R. E. Manual for the State-Trait Anxiety Inventory. Palo Alto, Calif: Consulting Psychologists Press, 1970.

Spielberger, C. D. Preliminary manual for the Test Anxiety Inventory. Palo Alto, Calif: Consulting Psychologists Press, 1980.

Tulving, E., \& Thомson, D. M. Encoding specificity and retrieval processes in episodic memory. Psychological Review, 1973, 80, 352-373.

Whitbourne, S. K. Test anxiety in elderly and young adults. International Journal of Aging and Human Development, 1976, 7, 201-210.

(Received for publication November 24, 1980.) 